\title{
Anesthetic Management for a Patient with Amyloidosis
}

\author{
Yoshihiro Hirabayashi, Satoshi Yokosuka, Koh Miyashita, \\ and Reiju Shimizu
}

(Key words: amyloidosis, anesthesia)

Amyloidosis is a disease in which a homogeneous eosinophilic substance, amyloid, deposits in various tissues and organs of the body, or in some restricted sites. Because its deposition is very insidious and variable in organ distribution $^{1}$, anesthetic management should be cautiously approached with regard to multisystem complications which can arise ${ }^{2}$. We report upon the anesthetic management of a patient with primary amyloidosis who presented congestive heart failure, renal failure, and technical problems with endotracheal intubation to the anesthesiologist during the perioperative period.

\section{Case Report}

A 68-yr-old male weighting $58 \mathrm{~kg}$ with primary amyloidosis admitted to our hospital to treat for pain, coldness and sensation of numbness in the right leg. Past medical histrory included myocardial infarction at the age of $55 \mathrm{yr}$, left ventricular hypertrophy diagnosed at the age of $62 \mathrm{yr}$ and atrial fibrillation diagnosed at the age of $64 \mathrm{yr}$. Confirmation of the diagnosis as primary amyloidosis was obtained at

Department of Anesthesiology, Jichi Medical School, Tochigi, Japan

Address reprint requests to Dr. Hirabayashi: Department of Anesthesiology, Jichi Medical School, Minamikawachi-machi, Kawachi-gun, Tochigi-ken, 329-04 Japan the age of $65 \mathrm{yr}$ by prostate biopsy which revealed abnormal deposits of amyloid. During the previous 3 years, congestive heart failure due to cardiac amyloidosis developed rapidly and his activity of daily life was severely limited by developed angina on effort despite treatment with isosorbide dinitrate. Diagnostic angiography revealed complete occlusion of the right femoral artery with thrombus, which required femoral artery bypass grafting. On the day after the angiography, he suffered from acute renal failure induced by iotholamate radiocontrast material. He required large amout of diuretics and continuous infusion of dopamine to improve urinary flow. The operation was scheduled when his general condition returned to the state on admission.

Preanesthetic examination revealed blood pressure 90/70 mmHg, pulse rate 88 beats $\min ^{-1}$, despite continuous infusion of dopamine (2 $\left.\mu \mathrm{g} \cdot \mathrm{kg}^{-1} \cdot \mathrm{min}^{-1}\right)$. There was no limitation of the neck and jaw movement but the tongue was slightly enlarged. His physical status was judged to be class 4 in the classification adopted by the New York Heart Association because of orthopnea. Hematological examination showed hemoglobin 10.0 $\mathrm{g} \cdot \mathrm{dl}^{-1}$, hematocrit $30.5 \%$, sodium 139 mEq. $l^{-1}$, potassium $3.6 \mathrm{mEq} \cdot l^{-1}$, chloride $104 \mathrm{mEq} \cdot l^{-1}$, urea nitrogen 28 Ing $\cdot \mathrm{dl}^{-1}$ and creatinine $1.2 \mathrm{mg} \cdot \mathrm{dl}^{-1}$. Ar- 
terial blood gas tensions were $\mathrm{PaCO}_{2}$ $33.8 \mathrm{mmHg}, \mathrm{Pa}_{\mathrm{O}_{2}} 64 \mathrm{mmHg}, \mathrm{pH} 7.50$ and Base Excess +5.1, while breathing room air. Electrocardiogram showed atrial fibrillation, low voltage of QRS complexes and abnormal $Q$ in leads II, III, ${ }_{a} V_{F}$ and $V_{1}-V_{4}$. Chest $X$-ray revealed an enlarged cardiac silhouette, pleural effusions and a ground glass appearance in lower lung field bilaterally. Premedication consisted of atropine, $0.5 \mathrm{mg}$, and hydroxyzine, $25 \mathrm{mg}$, intramuscularly $30 \mathrm{~min}$ before induction of anesthesia. The patient was taken to the operating room with a continuous infusion of dopamine $\left(2 \mu \mathrm{g} \cdot \mathrm{kg}^{-1} \cdot \mathrm{min}^{-1}\right)$ and with receiving oxygen $\left(21 \cdot \mathrm{min}^{-1}\right)$ via the nasal cannulae. Electrocardiographic leads and blood pressure cuff were applied; a 20-gauge intraarterial catheter to obtain arterial pressure and 18-gauge intravenous catheter were inserted. Following breathing oxygen for $5 \mathrm{~min}$, general anesthesia was induced with $0.35 \mathrm{mg}$ of fentanyl and $5 \mathrm{mg}$ of diazepam; and muscle relaxation was provided with $6 \mathrm{mg}$ of pancuronium. The patient's airway was appreciably difficult to maintain via a mask. Insertion of a oral-airway permitted adequate ventilation. The epiglottis was difficult to visualize because of the enlarged tongue. Intubation of the trachea was then accomplished with a $7.5 \mathrm{~mm}$ endotracheal tube by a fiberoptic bronchoscope. Anesthesia was maintained with $50-67 \%$ nitrous oxide in oxygen and additional dose of fentanyl $0.15 \mathrm{mg}$, diazepam $10 \mathrm{mg}$ and pancuronium $1 \mathrm{mg}$. Ventilation was manually controlled to maintain normocapnea. The central venous pressure (CVP) was measured by a catheter introduced through the right internal jugular vein. The initial CVP in the supine horizontal position was $37 \mathrm{cmH}_{2} \mathrm{O}$, that following the elevation of the patient's back up to 15 degrees (semi-Fowler's position) was $26 \mathrm{cmH}_{2} \mathrm{O}$, and the last CVP in the operating room was $21 \mathrm{cmH}_{2} \mathrm{O}$. The patient required $30 \mathrm{mg}$ of furosemide and continuous infusion of dopamine $\left(2-6 \mu \mathrm{g} \cdot \mathrm{kg}^{-1} \cdot \mathrm{min}^{-1}\right.$ ) to improve urinary flow. A total volume of $1,380 \mathrm{ml}$ of crystalloid was administered for $5 \mathrm{hr}$ in the operating room; urinary output during the same period was 1,000 ml. Postoperatively, the patient was transferred to the intensive care unit with ventilation controlled and close attention was given to the hydration and circulation. He was weaned from the ventilator over the next 4 days without serious complication, and discharged to the ward. Three month later, his congestive heart failure developed rapidly. Despite ventilatory and circulatory support, he died.

\section{Discussion}

Several types of clinical classification of amyloidosis have evolved ${ }^{3}$ : primary amyloidosis including familial amyloid polyneuropathy, secondary amyloidosis, amyloidosis accompanying multiple myeloma, and other forms of amyloidosis include localized accumulations and deposits associated with aging. Primary amyloidosis is the most common category of systemic amyloidosis seen today and develops without any known predisposing discase. The organs chiefly involved are the heart, skin, tongue, skeletal and visceral muscle, peripheral nerves and gastrointestinal tract. Secondary amyloidosis occurs as a sequel of prolonged inflammatory or infectious disease: notably rheumatoid arthritis, tuberculosis, leprosy and ankylosing spondylitis. Although the pattern of organ involvement may vary, parenchymal involvement of the liver, spleen, and kidney is the most frequent presentation. Amyloidosis accompanying multiple myeloma has been differentiated from secondary amyloidosis and has been reported in $6-15$ percent of the cases. 
The patient with systemic amyloidosis presents several problems to anesthesiologists during perioperative period. Symptomatic disturbances of cardiac rhythm, conduction and function are present in nearly all patients with primary amyloidosis, and are occasionally encountered in secondary amyloidosis. The most common manifestation of amyloid infiltration of the heart is congestive heart failure, often intractable to therapy ${ }^{4}$. Although digitalis is used for the treatment of congestive heart failure, patients with cardiac amyloidosis may very sensitivity to digitalis. This drug should be administered with special care. Atrial ventricular block may be seen in association with amyloid infiltration of the cardiac conduction systems ${ }^{5}$. Amyloid infiltration of the myocardium or pericardium leads up to stiffening of the heart, sometimes resulting in a syndrome resembling constrictive pericarditis.

Severe bradycardia or heart block developed during anesthesia was reported in patients with familial amyloid polyneuropathy ${ }^{6}$. Amyloid infiltration of the cardiac conduction tissues probably increases their susceptibility to anesthetic agents. Drugs that may adversely affect cardiac impulse initiation or conduction should be avoided. We avoided the use of succinylcholine and volatile anesthetic agents to reduce the risk of bradycardia and myocardial depression. The patient tolerated well to fentanyl and diazepam. No major changes in the heart rate or blood pressure occurred during the anesthesia. Atropine is widely used for the treatment of bradyarrhythmia or conduction blocks. However, it was reported that therapeutic or higher dose of atropine might be not only useless but also potentially detrimental for cardiac arrhythmias in some patients with familial amyloid polyneuropathy ${ }^{7}$. When bradyarrhythmias or conduc- tion blocks will be encountered during anesthesia, isoproterenol may have beneficial effects on those arrhythmias in such patients.

Renal amyloidosis may be manifested by proteinuria or by the nephrotic syndrome. Although our patient was not diagnosed as nephrotic syndrome with severe proteinuria, small amount of iotholamate radiocontrast material caused acute renal failure. The patient might be in the stage of severely decreased renal reserve. Careful attention should be paid to ventilation and circulation during perioperative period. Fluids also should be administered with caution. The volume of fluid administered must be carefully monitorred by pulse rate, blood pressure and CVP when indicated, as guides. If renal function has been deteriorated even further, a combination of low-dose dopamine plus furosemide may be tried. Asynergism between dopamine and furosemide in renal insufficiency has been described ${ }^{8}$.

Macroglossia is common and problems with tracheal intubation should be anticipated. In our patient, physical examination revealed a slightly enlarged tongue, but his macroglossia seemed to be not large enough to disturb visualization of the epiglottis. Tracheal intubation was initially attempted under direct laryngoscopy. However, visualization of the epiglottis by the laryngoscope blade was impossible because of the enlarged tongue that was too stiff to elevate. A endotracheal tube was then placed by a fiberoptic bronchoscope. The clinical importance is the fact that direct laryngoscopy may be more difficult than anticipated in some patients with amyloid infiltration in the tongue even if the tongue is not so large by appearances. Intubation with the patient awake may be preferable in such patients.

Amyloid infiltration of cutaneus blood vessels is responsible for purpura 
and intradermal infiltration causes bullous eruptions ${ }^{2}$. Coughing, straining or trauma that does not cause problems in the absence of amyloidosis may induce unexpected purpura or bullous eruption in the patient with systemic amyloidosis.

We reported a case of primary amyloidosis and discussed about the anesthetic problems in amyloidosis. Anesthetic management should be cautiously approached with regard to multisystem complications which can arise in systemic amyloidosis.

' (Received Jul. 15, 1991, accepted for publication Sep. 11, 1991)

\section{References}

1. Robbins SL, Cotran RS, Kumar V: Disease of immunity. In: Robbins SL (Ed). Pathologic Basis of Disease. 3rd ed., Philadelphia, WB Saunders, 1984, p158

2. Welch DB: Anaesthesia and amyloidosis. Anaesthesia 37:63-66, 1982

3. Calkins E: Amyloidosis. In: Wntrobe MM, Thorn GW, Adams RD, Braunwald E, Isselbacher KJ, Peters- dorf RG (Ed). Princeples of internal Medicine. 7th ed., New York, McGraw-Hill Book company, 644-647, 1974

4. Chew C, Ziady GM, Raphael MJ, et al: The functional defect in amyloid heart disease. The 'stiff heart' syndrome. Am J Cadiol 36:438-444, 1975

5. Roberts WC, Waller BF: Cardiac amyloidosis causing cardiac dysfunction: analysis of 54 necropsy patients. Am J Cardiol 52:137-146, 1983

6. Eriksson $\mathrm{P}$, Boman $\mathrm{K}$, Jacobsson $\mathrm{B}$, et al: Cardiac arrhythmias in familial amyloid polyneuropathy during anaesthesia. Acta Anaesthesiol Scand 30:317-320, 1986

7. Horio $\mathbf{Y}$, Matsuyama $\mathrm{K}$, Rokutanda $M$, et al: Electrophysiologic effects of atropine and isoproterenol on the cardiac conduction system in familial amyloid polyneuropathy. Jpn Circ J 48:474-483, 1984

8. Lindner A: Synergism of dopamine and furosemide in diuretic-resistant, oliguric acute renal failure. Nephron 33:121-126, 1983 